\title{
CLIMATE SIGNALS IN WINE QUALITY TIME-SERIES OF NORTH-EAST HUNGARY
}

\author{
KOSIK I. ${ }^{1}$, MIKA J. ${ }^{2}$, RAZSI A. ${ }^{2,3}$, GAL L. ${ }^{2}$
}

\begin{abstract}
Today's viticulture regions for quality wine production are located in relatively narrow geographical and therefore climatic niches that put them at greater risk from climate change than other more broad acre crops. Our target area, the Mátra Region is close to the edge of optimal wine production concerning its climate conditions. Fifty year (1961-2010) wine and quality (natural sugar content, in weight $\%$ of must) data are analysed and compared to parallel climate variables. Two sets of station-based monthly temperature, sunshine duration and precipitation data, taken from neighbouring stations, Eger-Kölyuktető (1961-2010) and Kompolt (1976-2006) are used altogether in 132 combinations. In addition, daily grid-point data provided by the CarpatClim Project are used (www.carpatclimeu.org/pages/home). By now it is clear that (1) wine quality, is in significant negative correlation with the annual precipitation and in positive correlation with temperature and sunshine duration. (2) Applying a wide combination of monthly data we obtain even stronger correlations (higher significance according to t-tests) even from the station-based data, but it is difficult to select and optimum model from the many proper combinations just slightly differing in performance over the test sample. (3) The interpolated areal averages of the grid-point data promise good results, but their statistical analysis by using 5-day averages is just in its initial phase. It is clearly seen that June 5-day temperature means strongly influence the sugar content in the Mátra-region of NE Hungary.
\end{abstract}

Keywords: wine quality, temperature, precipitation, sunshine duration, regression

\section{INTRODUCTION}

The grapevine is one of the oldest cultivated plants that, along with the process of making wine, have resulted in a rich geographical and cultural history of development.

Most of the vine growing areas are located between latitudes $30-50^{\circ}$ on the Northern Hemisphere, this belt corresponds to the $10-20^{\circ} \mathrm{C}$ annual isotherms. The most important climatic factors influencing viticulture production, yield and wine quality are broad structural conditions and singular weather events, like solar radiation (the number of sunshine hours, the site exposition), temperature, precipitation, moisture parameters (Jones et al., 2012; Malheiro et al. 2012). Due to the expected global warming shifts in viticulture zoning, advance in grapevine plant phenology, changes in pest migration and fungi occurrence are expected, as well as grape ripening properties may undergo changes, yield quantity and quality

\footnotetext{
${ }^{1}$ Gyongyos-Domoszlo State Farm, Gyöngyös, Hungary

${ }^{2}$ Eszterhazy Karoly University, Eger, Hungary. mika.janos@uni-eszterhazy.hu

${ }^{3}$ Regional Centre, Hungarian Meteorological Service, Miskolc, Hungary
} 
may be influenced by occurring water shortage, the style of the wines in different wine regions, or terroirs may also alter (Spellman, 1999; Schultz, 2000).

Viticulture regions for quality wine production are located in relatively narrow climatic niches that put them at greater risk from climate change than other broader acre crops. Our target area, the Mátra Region is fairly close to the edge of optimal wine production concerning its climate conditions.

Our study provides the first results of research trying to answer statistically how quantity and quality of grapevine yield is related to meteorological conditions. After introducing the Mátra region, where the grapevine data are from in Section 2, the grapevine data and the subsequently applied various meteorological data are described in Section 3, together with the applied regression calculations. Section 4 already presents the results grouped according to the applied sets of meteorological data. The paper is terminated by the Discussion, including further steps of research.

\section{THE MÁTRA GRAPEVINE GROWING REGION}

Wine has been produced in Hungary at least since Roman times. Nowadays, Hungary has 22 wine regions. The Mátra wine-growing region does not belong to the most famous ones, but this is the largest hill- and mountain wine region where good quality white wine is produced. The wine region reaches its market success mainly with its reductive, fruity wines. Its area is 7800 hectares. The Mátra wine region is located about 80 kilometres from Budapest on the southern slopes of the Mátra Mountain range in Northern Hungary (Fig 1).

The Mátra Mountains with their moderate climate and protected areas provide perfect growing conditions for the local vineyards. its soil consists of volcanic rock (andesite-rhyolite-tuff) covered by loess and sand. Its common grape varieties are MullerThurgau, which is fragrant, light, soft; Italian Riesling - dry, fresh acidic. Muscat-Ottonel (Muskotaly) - high alcohol contents, fragrant, high sugar degree. Though red wine production has gone largely back, Kekfrankos and Zweigelt wines are still produced.

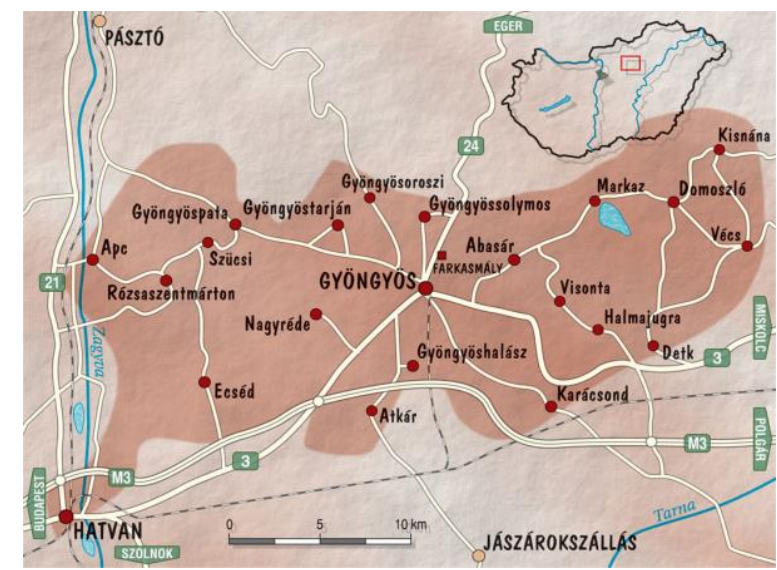

Fig. 1. The Mátra wine-producing region (7800 ha) with its position in Hungary 


\section{DATA AND METHODS \\ 3.1 Grapevine data}

As it is presented in Fig. 2, the harvested grapevine quantity exhibits two well expressed trends with different signs. Before ca. 1990 a growing tendency is present, accompanied by a decreasing trend after this year. The later trend does not mean more than the quantity became less important behind the quality, generally regulated by the grapevine owners in the form of cutting down a part of the forming yield from the vine stock.

Note the year 1985 which was hit by various extremities from strong winter frosts to weak spring yield fixation and various pests attacked the stocks. This year was both included and excluded into the analyses below, but the significance of the results were not changing too much. Hence, these specifics are not separately mentioned.

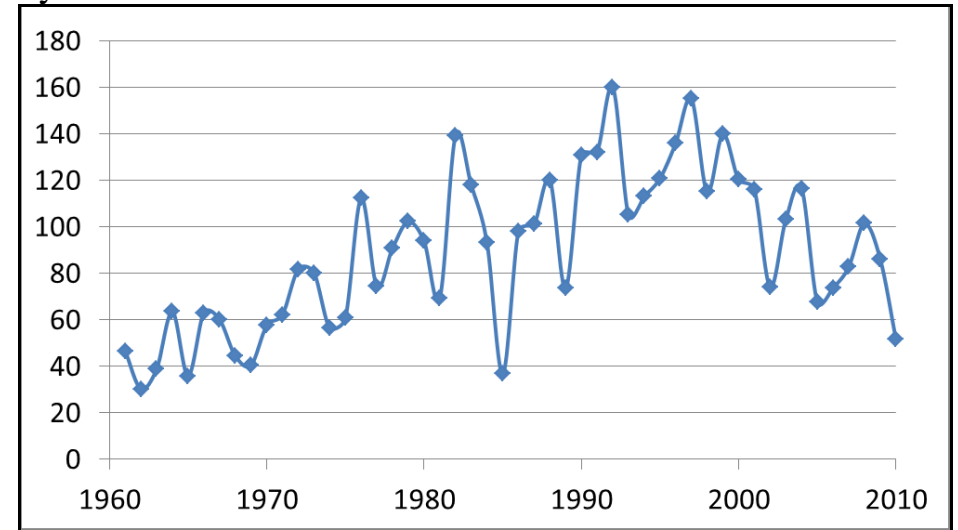

Fig. 2. Evolution of grapevine quantities (q/ha) in the Mátra region

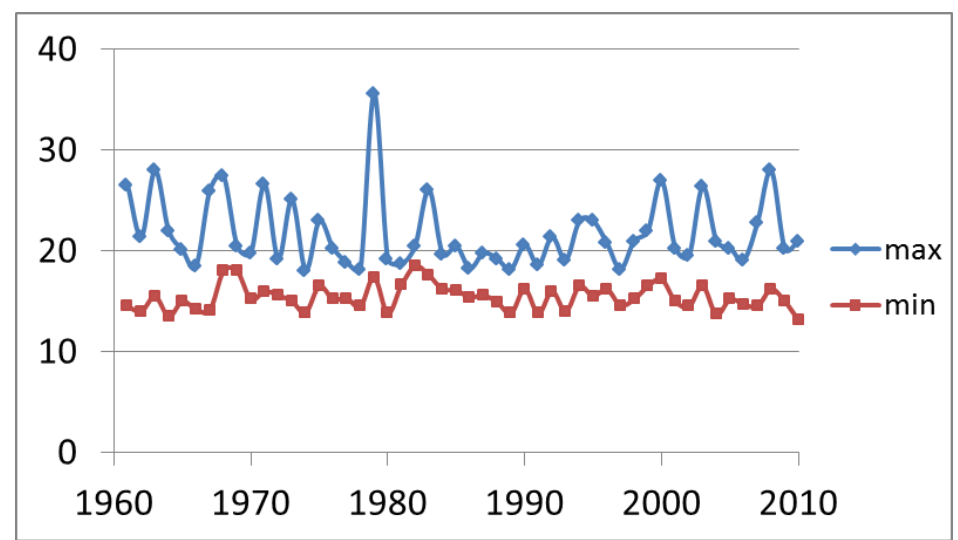

Fig. 3. Evolution of must quality (0.01 kg sugar/1 $\mathrm{kg}$ must) in the Mátra region, as registered by the personnel: maxima and minima of the given year are archived.

Fig. 3 and Fig 4 displays series of sugar content in its original form as the data are available, i.e. maxima and minima observed in the region (Fig. 3), and as transformed into averages as $(\max +\min ) / 2$ and spread of the sample (max-min). 
Fort he must sugar content there are no long-term trends observed, but large inter-annual variance is seen, likely in relation with weather of the given year.

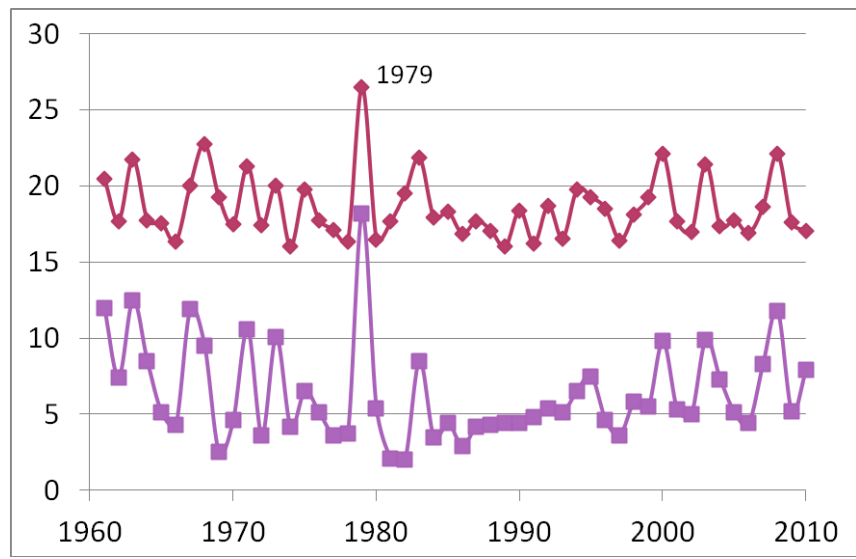

Fig. 4. Evolution of must quality (0.01 kg sugar/1 $\mathrm{kg}$ must) in the Mátra region, derived from the data in Fig 3: Average values and the annual spread of the extremes

\subsection{Station-based meteorological data}

Let's start with the annual time series used in first regression computations (Fig. 5).
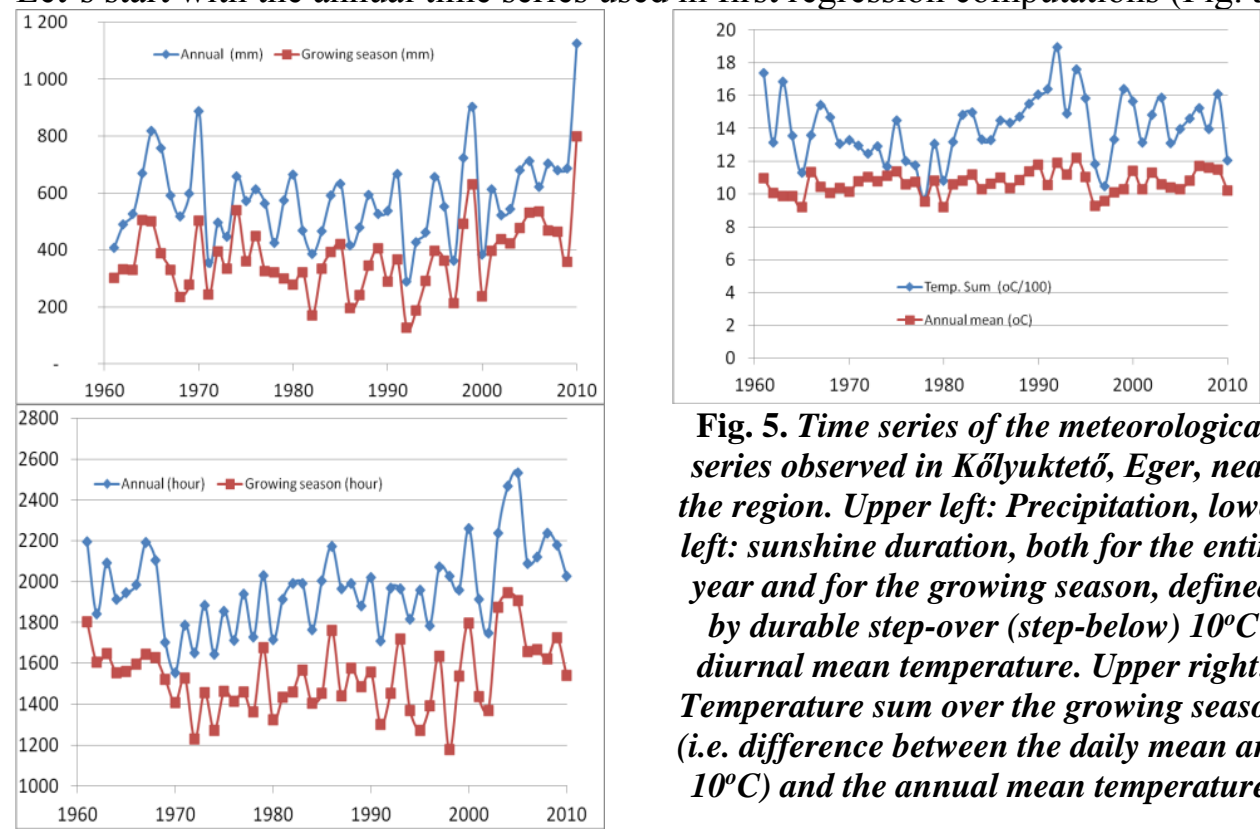

Fig. 5. Time series of the meteorological series observed in Kölyuktetö, Eger, near the region. Upper left: Precipitation, lower left: sunshine duration, both for the entire year and for the growing season, defined by durable step-over (step-below) $10^{\circ} \mathrm{C}$ diurnal mean temperature. Upper right: Temperature sum over the growing season (i.e. difference between the daily mean and $\left.10^{\circ} \mathrm{C}\right)$ and the annual mean temperature.

Six variables are seen in the Figure, the seventh is annual precipitation of the previous year. Of course, these variables are not independent of each other. Table 1 indicates the pair-wise correlation coefficients between the three variables related to the growing season in their original form, and as deviations from the 30 
and 20 years linear trends (1961-1990 and 1991-2010, as defined in connection with the yield amounts). All these data belong to the Eger, Kölyuktetö station.

Table 1. Correlation coefficients between the meteorological data of the growing season. The upper triangle relates to the original data, whereas the numbers in the lower and triangle indicate the correlation after $30+20$ years de-trending.

(The 95\% significance threshold is 0.27 . Values over this threshold are bold set.)

\begin{tabular}{|c|c|c|c|}
\hline & \multicolumn{3}{|c|}{ Original data } \\
\cline { 1 - 1 } & Precipitation & Temper. sum & Sunshine dur. \\
\cline { 1 - 1 } Precipitation & \multicolumn{3}{|c}{-0.21} \\
\cline { 1 - 1 } Temper. sum & -0.19 & -0.05 \\
\cline { 1 - 1 } Sunshine dur. & $\mathbf{- 0 . 4 1}$ & $\mathbf{0 . 3 3}$ & 0.25 \\
\cline { 1 - 1 } & \multicolumn{2}{|c|}{ Deviations from linear trends } \\
\hline
\end{tabular}

\subsection{The CarpatClim grid-point data}

The statistical analyse was also started based on daily grid-point data in $7 \times 11 \mathrm{~km}$ resolution, derived by experts of Hungarian Meteorological Service are available also via Internet (www.carpatclim-eu.org). The series exist for 19612010. The data underwent a process of homogenisation (MASH, SZENTIMREY, 1999) to avoid non-realistic fluctuations, and statistically optimum interpolation (MISH, SZENTIMREY and BIHARI, 2006). The latter uses not only the spatial correlation of the elements but also the temporal ones which is not known in any other spatial interpolation methodology. Both statistical processes are described by the authors at http://www.carpatclim-eu.org/docs/mashmish/mashmish.pdf.

\subsection{Uni- and multivariate correlation and regression}

Univariate correlation coefficients were computed and tested against the commonly used z-test, applied for the whole 50 years (1961-2010) period.

Stepwise multivariate regression approach has also been applied for a shorter 31 years period (1976-2006) for which monthly meteorological variables are available at the Kompolt station which is even closer to the grapevine region.

Monthly temperature, precipitation and sunshine duration data were used in monthly, bi-monthly, etc., annual versions stated from the previous November (October for precipitation). In this way, 126 variable-candidates were entered into the multiregression computations performed only for the must sugar content.

The multiregression process selected the strongest correlation to the dependent variable, than the second one from among the remained candidates, etc.

\section{RESULTS}

\subsection{Results with seven annual and growing season variables}

Yield amount does not exhibit significant correlation with the considered variables (Tab. 2), neither in the two periods with opposing tendencies nor in the whole 50 years period.

This is not the case for the sugar content (Tab. 3) where all three variables exhibit significant correlation both in the first 30 years and in the whole 50 years. The signs of the 
coefficients correspond to our a priori expectations, but the explained variances are $10-20 \%$ only. One expects stronger role played by meteorology in sugar formation of grapevine!

Table 2. Correlation coefficients between yield amount and climate variables of the growing season observed in the 30 and 20 years periods, and over 1961-2010. All variables are deviations from the separate linear trends (whether or not they are significant). The significant correlation coefficients are set bold.

\begin{tabular}{|c|c|c|c|}
\hline Deviation from trend & Precipitation & Temperature sum & Sunshine duration \\
\hline $30 \mathrm{yr}(1961-1990)$ & $-0,24$ & 0,04 & 0,04 \\
\hline $20 \mathrm{yr}(1991-2010)$ & $-0,26$ & $-0,13$ & 0,17 \\
\hline 50 years & $-0,24$ & $-0,03$ & 0,10 \\
\hline
\end{tabular}

The $95 \%$ thresholds for 30,20 and 50 years are $0.35,0.44$ és 0.27 , respectively

Table 3. Correlation coefficients between sugar content and climate variables of the growing season observed in the 30 and 20 years periods, and over 1961-2010. All variables are deviations from the separate linear trends (whether or not they are significant). The significant correlation coefficients are set bold.

\begin{tabular}{|c|c|c|c|}
\hline Deviation from trend & Precipitation & Temperature sum & Sunshine duration \\
\hline 30 yr (1961-1990) & $\mathbf{- 0 , 4 4}$ & $\mathbf{0 , 3 8}$ & $\mathbf{0 , 4 5}$ \\
\hline 20 yr (1991-2010) & -020 & 0,38 & 0,12 \\
\hline 50 years & $\mathbf{- 0 , 3 3}$ & $\mathbf{0 , 3 7}$ & $\mathbf{0 , 3 0}$ \\
\hline
\end{tabular}

The $95 \%$ thresholds for 30,20 and 50 years are $0.35,0.44$ és 0.27 , respectively

\subsection{Results with combinations of monthly data}

Using 126 combinations of monthly temperature sum, precipitation and sunshine duration, we obtain 126 potential independent variables. Surprisingly, the step-wise multiregression procedure, that decides on explained variances according to F-test, selected two variables, only. They are the temperature sum of June and sunshine duration of the May-October period. If comparing the regression coefficients to the average values, one can establish considerable effect of both meteo-variables.

Table 4. The best key variables explaining highest portion of variance in sugar content. The means are given to relate the regression coefficients. The mean must sugar degree was 18.3 for 1976-2006. The 95\% significance threshold for the multicorrelation is 0.35 .

\begin{tabular}{|c|c|c|c|}
\hline Key variable & Mean & Regression coefficient & Multicorrelation \\
\hline Temperature sum June & $571{ }^{\circ} \mathrm{C}$ & $2,9 \mathrm{deg} / 100{ }^{\circ} \mathrm{C}$ & 0.54 \\
\hline Sunshine duration May-Oct & 1340 hours & $0.7 \mathrm{deg} / 100$ hours & 0,62 \\
\hline
\end{tabular}




\subsection{First results with five-day gridded data}

Though significant coefficients were found for the shorter period with the nearby Kompolt station, further improvement of the meteorological data was applied in two aspects: (i.) Grid-point data were selected definitely for the Mátra region with spatial averages calculated. (ii.) This was performed for 5-day averages to refine the monthly averages, used in multi-regression calculations. At present we can show the first results of this computation:

Correlation coefficients between the sugar content and each 5-day period averages for temperature and sums for precipitation (Fig. 6) were calculated. We have 73 candidates for significant correlation in the year, so the $95 \%$ threshold means that we could find ca. 4 above threshold values even among totally random pairs of data.

In case of temperature, there are six values over the threshold in the midMay end of June period (27-36 pentads) which is unlikely random. This result supports the significance of June temperature obtained by the multi-regression applying strictly monthly data in the Kompolt station.

For precipitation there us just two 5-day periods with numerically overthreshold values, but they fall into the inactive period of grapevine, so we have no reason to consider them as real effects on the must quality.

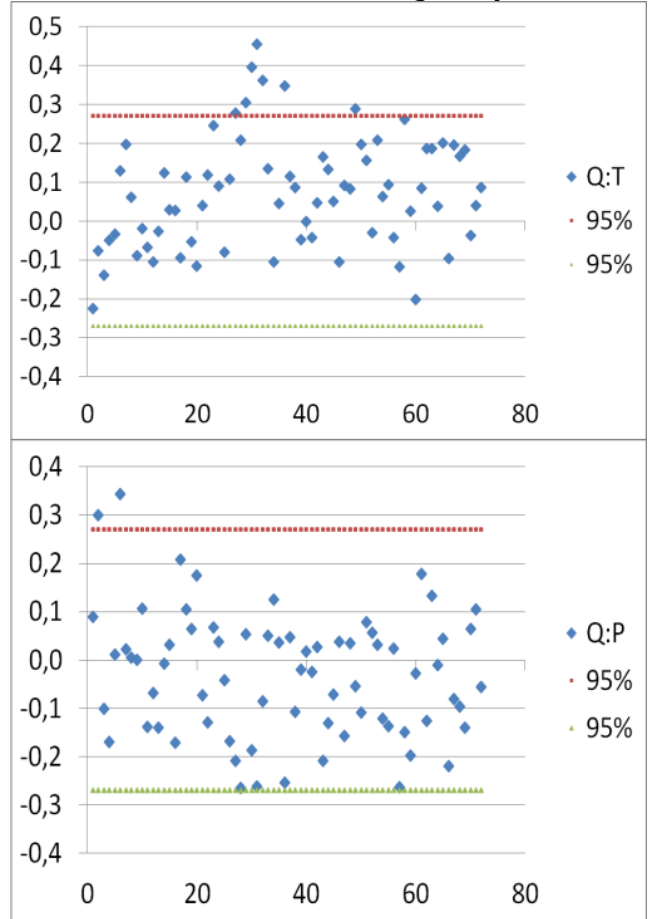

Fig. 7. Correlation between sugar content $(Q)$ and 5 -day values of temperature (upper) and precipitation (lower) with the significance thresholds also indicated 


\section{DISCUSSION}

Fifty year (1961-2010) wine quantity (t/ha) and quality (natural sugar content, in weight $\%$ of must) data are analysed in themselves and further compared to parallel climate variables. One set of station-based temperature, sunshine duration and precipitation data are taken from a neighbouring station, Eger Kölyuktetö, and grid-point data by CarpatClim Project are also used for comparison. By now it is clear that (1) wine amount is a year-by-year varying combination of natural productivity and man-made attempts to achieve better quality by thinning the grape clusters in spring. Therefore we separated a 30 years and a 20 years part breaking them by 1991. (2) However, wine quantity does not show considerable correlation with any of the parallel climate variable in either period. (3) Wine quality, however, is in significant negative correlation (regression) with the annual precipitation and positive correlation with temperature and sunshine duration. (4) Applying interpolated site-specific areal averages from the grid-point data, one may receive the qualitatively the same results but with higher significance.

Effects of weather and climate have always been in the focus of interest for the relevant scientists. The high-resolution CarpatClim data open new perspectives in the Carpathian Region. This 7x11 km diurnal data for 1961-2010 allows to relate climate data in area means defined according the location of the wine production data, instead of single stations in or near the wine region.

These diurnal data allow us to group the data of the phenological phases not being limited by e.g. monthly or decadal averages. Some other important moments of the research are: (i.) Use of classical multivariate statistics not being limited by linear approaches. (ii.) Knowledge of constant and of variable nonclimatic characteristics of any production site allows us a priori exclusion of few very extreme single years (e.g. 1985 in the Mátra region) and a posteriori identification of outlier years after the analysis.

\section{REFERENCES}

1. Jones, G.V., Reid, R., Vilks, A. (2012):The Climate, Grapes, and Wine: Structure and Suitability in a Variable and Changing Climate. In Geography of Wine. Regions, Terroir and Technics. (ed. P.H. Dougherty), Springer Verlag, pp.109-133

2. Malheiro, C., Santos, J. A., Pinto J. G., Jones, G. V. (2012): European viticulture geography in a changing climate. Le Bulletin de 1 O.I.V. 85 - N 971-973, 15-22

3. Schultz H.R. 2000. Climate change and viticulture: a European perspective on climatology, carbon dioxide and UV-B effects. Aust J Grape Wine Res. 6:2-12

4. Spellman G. 1999. Wine, weather and climate. Weather 54:230-239

5. Szentimrey T. (1999): Multiple Analysis of Series for Homogenization (MASH). Proceedings of the 2nd Seminar for Homogenization of Surface Climatological Data. Budapest; WMO. WCDMP-No. 41. pp. 27-46

6. Szentimrey T.. Bihari Z. 2006: MISH (Meteorological Interpolation Based on Surface Homogenized Data Basis). COST-719 Final Report. The use of GIS in climatology and meteorology. (O. E. TVEITO. et al. eds.) pp. 54-56 